\title{
Authors' reply to Notcutt
}

\author{
Fernanda B Fukushima assistant professor ${ }^{1}$, Dailson M Bezerra PhD student ${ }^{1}$, Paulo J F Villas \\ Boas associate professor ${ }^{2}$, Adriana P Valle associate professor ${ }^{2}$, Edison I O Vidal assistant \\ professor $^{2}$
}

${ }^{1}$ Anesthesiology Department, Universidade Estadual Paulista (UNESP), 18618-970, Botucatu, SP, Brazil; ${ }^{2}$ Internal Medicine Department, Universidade Estadual Paulista (UNESP), 18618-970, Botucatu, SP, Brazil

We agree with Notcutt that prompt referral of patients with complex regional pain syndrome to specialty pain clinics is essential. ${ }^{12}$ This belief is shared by most pain medicine specialists and is reaffirmed by management guidelines..$^{3-5}$ However, when searching the literature to write the article we were alarmed by the lack of good quality evidence supporting this belief. Obviously, it would be unethical for a clinical trial to randomise patients to early or late referral to a specialty pain clinic. However, current knowledge on the epidemiology of the syndrome is so limited that our belief could stem from selection bias-specialists in pain medicine tend to see patients with the most severe signs and symptoms, and it is possible that patients with milder forms of the syndrome might experience early resolution. In fact, one retrospective population based study found that 55 of 74 patients with complex regional pain syndrome experienced complete pain resolution and needed no further drug treatment for pain. ${ }^{6}$

We also agree that, given the possibility of severe outcomes (refractory pain and disability), most patients with anything but mild symptoms should be promptly referred to specialty pain clinics. However, as well as suspecting the diagnosis and referring patients to pain clinics, GPs can play an important role in the co-management of patients with the syndrome. For example, GPs can start patients on drugs for the treatment of neuropathic pain and provide guidance to patients on behavioural strategies to cope with chronic pain in order to decrease symptoms and disability.

Competing interests: None declared.

Full response at: www.bmj.com/content/348/bmj.g3683/rr/760592.

1 Notcutt WG. Early management of complex regional pain syndrome is crucial. BMJ 2014;349:g4704

2 Fukushima FB, Bezerra DM, Villas Boas PJF, Valle AP, Vidal EIO. Complex regional pain syndrome. BMJ 2014;348:g3683. (25 June.)

3 Royal College of Physicians. Complex regional pain syndrome in adults: UK guidelines for diagnosis, referral and management in primary and secondary care. 2012. https:// www.rcplondon.ac.uk/sites/default/files/documents/complex-regional-pain-full-guideline.

4 Perez RS, Zollinger PE, Dijkstra PU, Thomassen-Hilgersom IL, Zuurmond WW, Rosenbrand $\mathrm{KC}$, et al. Evidence based guidelines for complex regional pain syndrome type 1. BMC Neurol 2010;10:20.

5 Harden RN, Oaklander AL, Burton AW, Perez RS, Richardson K, Swan M, et al. Complex regional pain syndrome: practical diagnostic and treatment guidelines, 4 th ed. Pain Med 2013;14:180-229.

6 Sandroni P, Benrud-Larson LM, McClelland RL, Low PA. Complex regional pain syndrome type I: incidence and prevalence in Olmsted county, a population-based study. Pain 2003;103:199-207.

Cite this as: BMJ 2014;349:94710

(๑) BMJ Publishing Group Ltd 2014 